\title{
Analisis Perbandingan Aggregat Of Function (AOF) dengan Non-Dominated Sorting Genetic Algorithm (NSGA-II) dalam Menentukan Optimasi Multi-Objective pada Penjadwalan Mesin Produksi Flow Shop
}

\author{
Fifin Sonata*, Dede Prabowo Wiguna** \\ *,** Program Studi Sistem Informasi, Sekolah Tinggi Ilmu Komputer Medan
}

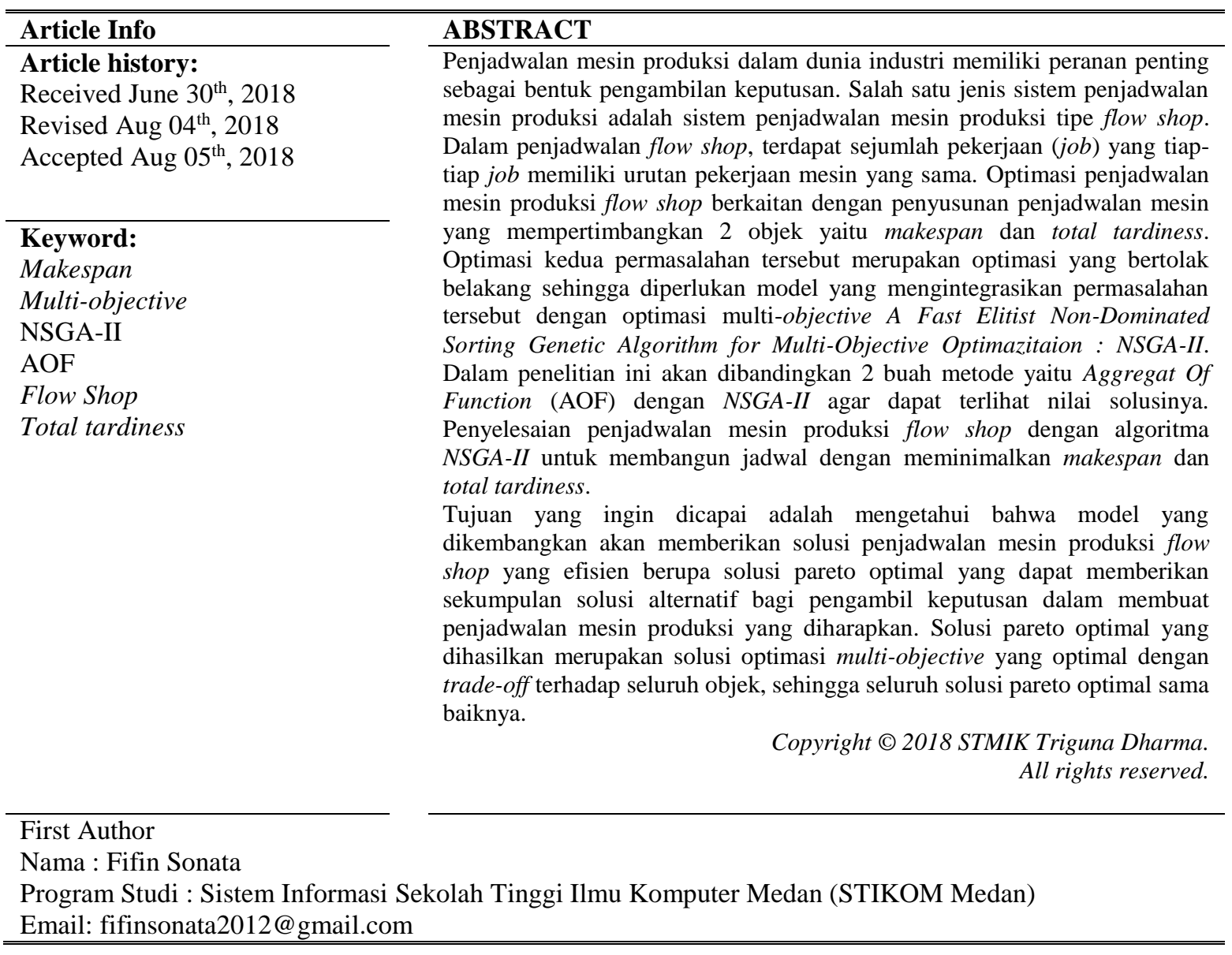

\section{PENDAHULUAN}

Penjadwalan mesin produksi di dalam dunia industri, baik industri manufaktur maupun agroindustri memiliki peranan penting sebagai bentuk pengambilan keputusan. Perusahaan berupaya untuk memiliki penjadwalan yang paling efektif dan efisien sehingga dapat meningkatkan produktivitas yang dihasilkan dengan total biaya dan waktu seminimal mungkin. Salah satu model yang dapat diterapkan dalam keadaan made-to-order pada perusahaan manufaktur adalah model penjadwalan flow shop.

Dalam penjadwalan flowshop, terdapat sejumlah pekerjaan (job) yang tiap-tiap job memiliki urutan pekerjaan mesin yang sama. Suatu penjadwalan dapat dimodelkan sebagai permasalahan penjadwalan flowshop apabila urutan pekerjaannya selaras. Permasalahan penjadwalan mesin produksi biasanya terletak pada penyusunan dan pengaturan job-job yang akan di proses pada serangkaian mesin. Salah satu kesulitan dalam melakukan penyusunan dan pengaturan job terhadap mesin yang tersedia adalah sulitnya mencari teknik-teknik yang tepat untuk membuat model penjadwalan mesin produksi yang optimal dan memenuhi segala kriteria-kriteria penjadwalan yang telah ditetapkan. 
Penjadwalan flow shop berkembang dari single-objective (optimasi dengan satu fungsi) menjadi multiobjective (optimasi dengan beberapa fungsi objektif). Dalam kasus multi-objective, akan dihasilkan sekumpulan solusi optimal yang dikenal dengan pareto-optimal solutions (solusi pareto-optimal) [4].

Beberapa penelitian telah mengembangkan model yang berkaitan dengan penjadwalan mesin produksi flow shop, baik yang menggunakan optimasi single-objective ataupun multi-objective. Penelitian yang hampir serupa juga pernah dilakukan oleh beberapa ahli diantaranya [1],[2],[11]dan [3]. [12] meneliti 2 fungsi objektif yaitu makespan dan total flow time. Secara umum, semua penelitian diatas memiliki kinerja komputasi yang baik, mampu memformulasikan secara matematis fungsi objektif dalam penjadwalan flow shop. Tetapi sebagian besar metode yang digunakan hanya mampu menyelesaikan permasalahan secara dependent yaitu hanya dapat digunakan pada permasalahan tertentu bergantung pada jenis permasalahan (heuristic).

Dalam kasus optimasi multi-objective, algoritma Non-Dominated Sorting Genetic Algorithm for Multiobjective Optimization : NSGA-II yang merupakan kelompok Algoritma Metaheuristic yang telah diuji kehandalannya dibandingkan dengan optimasi multi-objective lainnya. NSGA-II merupakan metode pengembangan dari Genetik Algoritma (GA) dan NSGA. Dibandingkan dengan GA dan NSGA, NSGA-II dibedakan pada penggunaan operator crowding distance agar menghasilkan solusi pareto optimal yang lebih baik. Penelitian menggunakan NSGA-II [8] yang meneliti tentang multi-objective untuk vehicle routing problems, [9] melakukan penelitian kasus optimasi multi-objective pada kasus managemen portofolio dan [4] membuat penelitian yang mampu menciptakan metode baru bernama omni optimizer yang di adopsi dari NSGA-II untuk kasus optimasi baik single maupun multi-objective.

Dari permasalahan di atas, maka perlu dilakukan penelitian untuk menganalisis perbandingan antara metode Aggregat of Function (AOF) yang prinsipnya menerapkan optimasi single-objective seperti Algoritma Genetika pada permasalahan multi-objective dengan algoritma multi-objective NSGA-II dalam penjadwalan mesin produksi flow shop untuk mengoptimalkan 2 fungsi objektif yaitu makespan dan total tardiness sehingga memberikan sekumpulan solusi alternatif bagi pengambil keputusan.

\section{METODE PENELITIAN}

\subsection{Jenis Penelitian}

Penelitian ini menggunakan metode penelitian kuantitatif. Dimana data yang diolah berupa angka sedangkan ouput yang dihasilkan berupa angka dan chart statistik. Pada penelitian ini menguji 2 algoritma yang berbeda yaitu AOF dan NSGA-II pada penjadwalan mesin produksi flow shop.

\subsection{Lokasi Penelitian} Medan.

Lokasi penelitian dilakukan di Laboratorium Komputer Sekolah Tinggi Ilmu Komputer (STIKOM)

\subsection{Alat Penelitian}

Penelitian ini menggunakan software yang mendukung untuk mengolah dan analisa data seperti uji normalitas dan uji homogenitas yaitu dengan menggunakan software SPSS. Selain itu juga menggunakan software penunjang yaitu MathLab dan Dreamweaver.

\subsection{Metode dan Desain Penelitian}

Dalam optimasi penjadwalan flow shop mesin produksi akan di bandingkan nilai makespan dan total tardiness sebelum dan sesudah diterapkannya optimasi multi-objective NSGA-II. Secara umum, diagram alir rancangan penelitiannya dapat digambarkan pada gambar 1 .

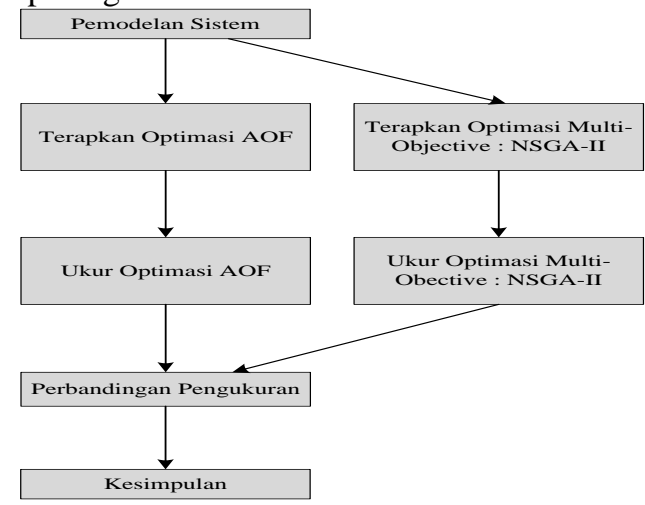

Gambar 1. Diagram Alir Rancangan Penelitian 


\subsection{Pengumpulan Data}

Untuk menguji sistem, data yang diujikan berupa data sekunder yang diperoleh dari Eva Instances [6], [10] : http://www.upv.es/gio/rruiz yang terdiri dari 110 instance kasus data yang akan diujikan.

Tabel 1. Tabel Data Penjadwalan Mesin Produksi

\begin{tabular}{|c|c|c|c|c|c|c|c|}
\hline Job/Mesin & $\mathrm{M}_{1}$ & $\mathrm{M}_{2}$ & $\mathrm{M}_{3}$ & $\mathrm{M}_{4}$ & $\ldots$ & $\mathrm{M}_{\mathrm{n}}$ & $\begin{array}{c}\text { Due- } \\
\text { Date }\end{array}$ \\
\hline $\mathrm{J}_{1}$ & 10 & 13 & 4 & 32 & $\ldots$ & 100 & 6 \\
\hline $\mathrm{J}_{2}$ & 24 & 30 & 4 & 70 & $\ldots$. & 80 & 8 \\
\hline$\ldots$. & $\ldots$. & $\ldots$. & $\ldots$. & $\ldots$ & $\ldots$ & $\ldots$. & $\ldots$ \\
\hline $\mathrm{J}_{\mathrm{n}}$ & 18 & 66 & 1 & 43 & $\ldots$. & 95 & 9 \\
\hline
\end{tabular}

Data-data tersebut diselanjutnya akan digunakan untuk memodelkan sistem dan diproses dengan menggunakan metode $A O F$ dan algoritma Multi-objective : NSGA-II. Kemudian hasilnya akan dibandingkan.

\subsection{Pemodelan Sistem}

Untuk mendapatkan solusi yang optimal dengan algoritma multi-objective NSGA-II, maka permasalahan penjadwalan mesin produksi flow shop akan dimodelkan secara matematis dalam bentuk persamaan multi-objective yang terdiri beberapa fungsi objektif dan pembatas. Persamaan multi-objective terdiri dari dua buah fungsi objektif yaitu fungsi yang memformulasikan nilai makespan, serta fungsi yang memformulasikan total tardiness.

Selain itu perlu untuk mendefinisikan variabel solusi yang ingin dihasilkan, sebab optimasi NSGA-II dimulai dengan inisialisasi populasi secara acak sesuai dengan definisi variabel solusi.

\subsection{Tahapan NSGA-II}

Optimasi Multi-objective : NSGA-II yang digunakan untuk mencari solusi pareto-optimal dari model matematis multi-objective dapat dibagi menjadi tahapan-tahapan yaitu Inisialisasi Populasi, Non-Dominated Sort, Crowding Distance, Seleksi, Operator Genetika, crossover, mutasi, Rekombinasi.Dimana pada beberapa tahapan diatas, akan ditentukan prosedur yang lebih rinci untuk penerapan NSGA-II pada permasalahan penjadwalan mesin produksi flow shop. Diagram alir secara umum dari NSGA-II ditampilkan dalam Gambar 2 dibawah ini.

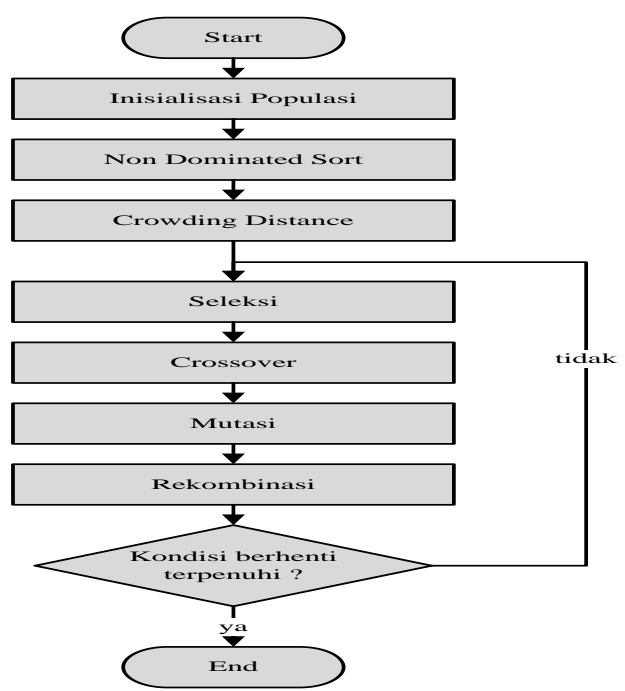

Gambar 2. Diagram Alir Umum NSGA-II

\subsection{Pengukuran dan Perbandingan Optimasi Menggunakan NSGA-II}

Hasil optimasi multi-objective NSGA-II akan diukur dan dibandingkan dengan hasil optimasi dengan AOF, dengan cara menghitung dan membandingkan hasil dari kedua fungsi objektif yaitu makespan dan total tardiness menggunakan optimasi AOF dengan NSGA-II. 
Untuk mengevaluasi kualitas populasi solusi yang dihasilkan oleh NSGA-II, akan digunakan indikator hypervolume [13] dan [14]. Indikator hypervolume didefinisikan sebagai volume dari seluruh kemungkinan solusi yang didominasi oleh sekumpulan solusi yang dihasilkan EMO. Semakin besar nilai hypervolume maka semakin baik solusi dari EMO tersebut. Pendekatan Monte Carlo digunakan untuk memperkirakan hypervolume dengan menghitung sekumpulan nilai acak pada ruang solusi yang didominasi oleh solusi dari EMO.

Karena NSGA-II merupakan algoritma stokastik, maka perlu dilakukan analisis statistik dari hasil penelitian yang diperoleh agar hasil tersebut dapat dibandingkan dengan tingkat kepercayaan tertentu. Uji normalitas dan uji homogenitas akan dilakukan terlebih dahulu, agar dapat ditentukan uji selanjutnya untuk membandingkan rata-rata hasil penelitian. Uji normalitas yang digunakan adalah uji Kolmogorov-Smirnov dan uji Shapiro-Wilk, sedangkan uji homogenitas menggunakan uji Levene. Hasil penelitian yang berdistribusi normal dengan variansi yang homogen akan diselesaikan dengan uji ANOVA, sedangkan untuk yang berdistribusi normal dengan variansi tidak homogen maka digunakan uji Welch

\subsection{Analisis Data}

Analisis Data menggunakan model matematis :

[12] telah memformulasikan permasalahan minimasi makespan dengan model matematis sebagai berikut :

$M(S)=\mathrm{C}_{\mathrm{m}, \mathrm{n}}$

$\mathrm{C}_{\mathrm{m}, \mathrm{n}}=\max \left\{\mathrm{C}_{\mathrm{m}-1, \mathrm{n}}, \mathrm{C}_{\mathrm{m}, \mathrm{n}-1}\right\}+\mathrm{t}_{\mathrm{m}, \mathrm{n}}$

Dimana :

$$
\begin{array}{ll}
\mathrm{M}(\mathrm{S}) & =\text { makespan (waktu untuk memproses seluruh job hingga selesai) } \\
\mathrm{C}_{\mathrm{m}, \mathrm{n}} & =\text { waktu komplit (completion time) job ke }-\mathrm{m} \text { pada mesin ke }-\mathrm{n} \\
\mathrm{t}_{\mathrm{m}, \mathrm{n}} & =\text { waktu proses untuk job m pada mesin } \mathrm{n} \\
\mathrm{m} & =\text { jumlah total job dalam penjadwalan } \\
\mathrm{n} & =\text { jumlah total mesin dalam penjadwalan }
\end{array}
$$

selain memformulasikan makespan, juga memformulasikan permasalahan minimasi total tardiness dengan model matematis sebagai berikut :

$T=\sum_{i=0}^{n} \max \left[0, \mathrm{C}_{\mathrm{i}}-\mathrm{d}_{\mathrm{i}}\right]$

Dimana :

$\mathrm{T}=$ total tardiness (total waktu terlambat suatu job dapat diselesaikan lebih cepat dari due-date-nya)

$\mathrm{C}_{\mathrm{i}} \quad$ = waktu komplit dimana seluruh mesin menyelesaikan suatu proses pada job $\mathrm{i}$

Sehingga dari persamaan (1) sampai dengan persamaan (3) dapat dimodelkan menjadi sebuah permasalahan multi-objective dengan model matematis sebagai berikut :

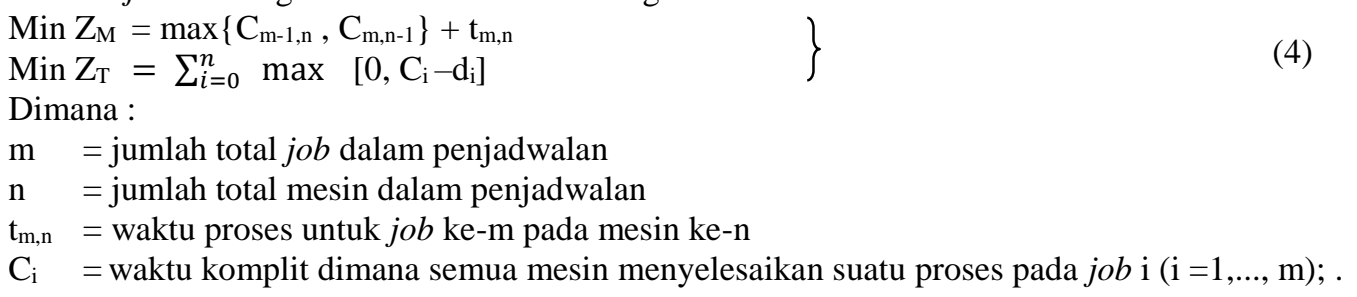

\section{ANALISA DAN HASIL}

\subsection{ANALISA}

\subsubsection{Model Matematis}

Selain [12] yang telah memformulasikan permasalahan minimasi makespan dengan model matematis pada persamaan 2, pada penelitian ini juga menggunkanan persamaan matematis yang telah sebagai berikut :

$$
T=\sum_{i=0}^{n} \max \quad\left[0, \mathrm{C}_{\mathrm{i}}-\mathrm{d}_{\mathrm{i}}\right]
$$

Dimana: $\mathrm{T}=$ total tardiness (total waktu terlambat suatu job dapat diselesaikan lebih cepat dari due-date-nya), $\mathrm{C}_{\mathrm{i}}=$ waktu komplit dimana seluruh mesin menyelesaikan suatu proses pada job $\mathrm{i}$

Sehingga dari persamaan (1) sampai dengan persamaan (5) dapat dimodelkan menjadi sebuah permasalahan multi-objective dengan model matematis sebagai berikut :

$$
\left.\begin{array}{ll}
\operatorname{Min} \mathrm{Z}_{\mathrm{M}} & =\max \left\{\mathrm{C}_{\mathrm{m}-1, \mathrm{n}}, \mathrm{C}_{\mathrm{m}, \mathrm{n}-1}\right\}+\mathrm{t}_{\mathrm{m}, \mathrm{n}} \\
\operatorname{Min} \mathrm{Z}_{\mathrm{T}} & =\sum_{i=0}^{n} \max \left[0, \mathrm{C}_{\mathrm{i}}-\mathrm{d}_{\mathrm{i}}\right]
\end{array}\right\}
$$

Dimana : $\mathrm{m}=$ jumlah total job dalam penjadwalan, $\mathrm{n}=$ jumlah total mesin dalam penjadwalan, $\mathrm{t}_{\mathrm{m}, \mathrm{n}}=$ waktu proses untuk job ke-m pada mesin ke-n, $\mathrm{C}_{\mathrm{i}}=$ waktu komplit dimana semua mesin menyelesaikan suatu proses pada job i $(\mathrm{i}=1, \ldots, \mathrm{m})$;

\subsubsection{Implementasi Tahapan NSGA-II}

Optimasi multi-objective NSGA-II yang digunakan untuk mencari solusi model matematis dari Persamaan (7) terbagi atas beberapa tahapan sebagai berikut : 
1. Inisialisasi Populasi

Populasi diinisialisasi secara acak, namun harus tetap mematuhi kaidah pembatas dari model matematis.

2. Non-Dominated Sort

Populasi yang telah diinisialisasi lalu diurutkan berdasarkan non domination menggunakan algoritma Fast Non-dominated Sorting yang didefinisikan oleh Deb [4] sebagai berikut :

- Untuk setiap individu $p$ di populasi $P$, dilakukan :

- $\quad$ Inisialisasi $S_{p}=\varnothing$. Himpunan ini akan berisi semua individu yang didominasi oleh $p$.

- $\quad$ Inisialisasi $n_{p}=0$. Menunjukkan jumlah individu yang mendominasi individu $p$.

- $\quad$ Untuk setiap individu $q$ di $P$

* Jika $p$ mendominasi $q$ maka tambahkan $q$ ke himpunan $S_{p}$. $\left(S_{p}=S_{p} \cup q\right)$

* Jika $q$ mendominasi $p$ maka increment counter dominasi $n_{p} .\left(n_{p}=n_{p}+1\right)$

- $\quad$ Jika $n_{p}=0$ berarti tidak ada individu yang mendominasi $p$ sehingga $p$ berada di front pertama; Beri nilai peringkat $p$ menjadi satu $\left(p_{\text {rank }}=1\right)$. Tambahkan $p$ ke front pertama $\left(F_{1}=F_{1} \cup\{p\}\right)$

- Inisialisasi counter front dengan satu $(i=1)$

- Selama front yang ke- $i$ tidak kosong $\left(F_{i} \neq \varnothing\right)$, lakukan :

$$
\text { - } Q=\varnothing
$$

- $\quad$ Untuk setiap individu $p$ di front $F_{\mathrm{i}}$

$$
\text { * } \quad \text { Untuk setiap individu } q \text { pada } S p
$$

- $n_{q}=n_{q}-1$, decrement jumlah dominasi untuk individu $q$

- jika $n_{q}=0$ maka tidak ada individu di front berikutnya yang mendominasi $q$, sehingga nilai $q_{\text {rank }}=i+1$. Tambahkan $q$ ke $Q(Q=Q \cup q)$.

- increment couter front dengan satu $(i=i+1)$

- $Q$ menjadi front berikutnya $\left(F_{\mathrm{i}}=Q\right)$

3. Crowding Distance

Crowding distance digunakan sebagai pembanding antara dua individu dalam front yang sama, agar solusi yang dihasilkan dapat mewakili keseluruhan solusi pareto-optimal.

Cara untuk menghitung crowding distance didefiniskan oleh [5] adalah sebagai berikut :

- Untuk setiap individu pada front $F_{\mathrm{i}}$, dengan $\mathrm{n}$ adalah jumlah individu

- Inisialisasi jarak dengan nol untuk semua individu $\left(F_{\mathrm{i}}\left(d_{j}\right)=0\right)$, dimana $j$ menunjukkan individu ke- $j$ pada front $F_{\mathrm{i}}$

- Untuk setiap fungsi tujuan $m$

* Urutkan individu di front $F_{\text {i }}$ berdasarkan nilai obyektif $m$

* Beri nilai tak terhingga untuk jarak individu pertama dan terakhir $\left(I\left(d_{1}\right)=\infty\right.$ dan $\left.I\left(d_{n}\right)=\infty\right)$

* Untuk $k$ mulai dari 2 sampai $(n-1)$

- $\quad I\left(d_{\mathrm{k}}\right)=I\left(d_{\mathrm{k}}\right)+\frac{I(k+1) \cdot m-I(k-1) \cdot m}{f_{m}^{\text {max }}-f_{m}^{\min }}$

- $\quad I(k) . m$ adalah nilai obyektif $m$ untuk individu $k$ pada $I$

4. Seleksi

Digunakan adalah Roulette Wheel Selection. Pada metode roda rolet kromosom orang tua (parents) yang akan dipindah-silangkan dipilih berdasarkan nilai fitnessnya. Nilai fitness dari masing-masing kromosom dibagi dengan total nilai fitness seluruh kromosom yang ada pada populasi. Setiap kromosom dianggap merupakan potongan/bagian dari roda rolet dengan ukuran potongan yang proporsional dengan nilai fitnessnya. Suatu nilai target antara angka nol dan angka satu ditetapkan secara acak. Kemudian roda rolet diputar sebanyak $\mathrm{N}$ kali, dimana $\mathrm{N}$ adalah jumlah individual atau kromosom dalam populasi. Dari setiap putaran, kromosom dengan nilai fitness yang berada di bawah nilai target dipilih untuk menjadi parents bagi generasi berikutnya.

5. Operator Genetika

Operator genetika yang digunakan adalah Precedence Preservative Crossover (PPX) untuk crossover dan operator mutasi adalah remove dan insert mutasi. PPX [7] dapat dijelaskan sebagai berikut :

a. String baru disusun secara acak dari allele string induk.

b. Angka acak 1 atau 2 dipakai untuk memilih induk.

c. Jika 1 diturunkan allele paling kiri dari induk pertama, jika 2 diturunkan allele paling kiri dari induk kedua. Selanjutnya terpilih tadi dihapus dari kedua induk.

d. Proses dilakukan sampai karakter di kedua induk habis. 
6. Rekombinasi

Populasi hasil crossover dan mutasi kemudian dikombinasikan dengan populasi induk yang kemudian dipilih dengan Non-Dominated Sort dan Crowding Distance untuk mendapatkan populasi generasi berikutnya.

\subsection{HASIL}

Data yang akan digunakan dalam penelitian adalah data yang diambil dari Eva Instances: [6]. Data yang diujikan pada penelitian terdiri dari 150 Job 30 Mesin disebut dengan Instance I_150_30 dan 250 Job 50 Mesin disebut dengan Instance I_250_50.

\subsubsection{Optimasi penjadwalan mesin produksi menggunakan AOF}

Pada prinsipnya, metode ini menerapkan optimasi single-objective seperti Algoritma Genetika pada permasalahan multi-objective.

Kedua fungsi objektif pada persamaan (6) digabung menjadi sebuah fungsi objektif yang baru dengan operator penjumlahan (+) dan masing-masing fungsi diberi bobot antara 0 dan 1 , dimana jumlah kedua bobot tersebut harus sama dengan 1. Fungsi objektif baru dari hasil penggabungan dari kedua fungsi objektif. Persamaan (7) adalah : Min $Z=\alpha *\left(\max \left\{\mathrm{C}_{\mathrm{i}-1, \mathrm{j}}, \mathrm{C}_{\mathrm{i}, \mathrm{j}-1}\right\}+\mathrm{t}_{\mathrm{i}, \mathrm{j}}\right)+(1-\alpha) *\left(\sum_{i=0}^{n} \max \left[0, \mathrm{c}_{\mathrm{i}}-\mathrm{d}_{\mathrm{i}}\right]\right)$ dengan $\alpha$ adalah bobot bernilai antara 0 dan 1. Digunakan Algoritma Genetika, dengan penentuan bobot $\alpha$ dilakukan melalui penelitian dengan variasi $\alpha=0,1,0,5$ dan 0,9 yang datanya ditabulasikan dalam Tabel 2 dan Tabel 3 dibawah ini.

Tabel 2. Hasil Penelitian AOF Instance I_150_30

\begin{tabular}{|c|c|c|c|c|c|c|}
\hline \multirow{2}{*}{$\alpha$} & \multirow{2}{*}{ Parameter } & \multicolumn{5}{|c|}{ Hasil Penelitian } \\
\hline & & 1 & 2 & 3 & 4 & 5 \\
\hline \multirow{3}{*}{0,1} & $\mathrm{ZM}$ & 11327 & 11153 & 11192 & 11200 & 11162 \\
\hline & $\mathrm{ZT}$ & 133433 & 119589 & 123218 & 122785 & 129088 \\
\hline & Jumlah Generasi & 178 & 255 & 140 & 251 & 209 \\
\hline \multirow{3}{*}{0,5} & $\mathrm{ZM}$ & 11049 & 11332 & 11333 & 11184 & 11258 \\
\hline & $\mathrm{ZT}$ & 130392 & 134616 & 138815 & 130638 & 130654 \\
\hline & Jumlah Generasi & 294 & 176 & 157 & 324 & 226 \\
\hline \multirow{3}{*}{0,9} & $\mathrm{ZM}$ & 11046 & 11345 & 11228 & 11464 & 10994 \\
\hline & ZT & 121534 & 137081 & 139031 & 154819 & 129969 \\
\hline & Jumlah Generasi & 188 & 158 & 138 & 173 & 220 \\
\hline
\end{tabular}

Tabel 3. Hasil Penelitian AOF Instance I_250_50

\begin{tabular}{|c|c|c|c|c|c|c|}
\hline \multirow{2}{*}{$\alpha$} & \multirow{2}{*}{ Parameter } & \multicolumn{5}{|c|}{ Hasil Penelitian } \\
\hline & & 1 & 2 & 3 & 4 & 5 \\
\hline \multirow{3}{*}{0,1} & $\mathrm{ZM}$ & 19196 & 19731 & 19422 & 19689 & 19459 \\
\hline & $\mathrm{ZT}$ & 453440 & 479169 & 522631 & 534560 & 482118 \\
\hline & Jumlah Generasi & 500 & 268 & 256 & 125 & 374 \\
\hline \multirow{3}{*}{0,5} & $\mathrm{ZM}$ & 19750 & 19459 & 19380 & 19584 & 19615 \\
\hline & $\mathrm{ZT}$ & 508587 & 505159 & 471894 & 497512 & 539113 \\
\hline & Jumlah Generasi & 169 & 165 & 270 & 294 & 180 \\
\hline \multirow{3}{*}{0,9} & $\mathrm{ZM}$ & 19773 & 19599 & 19442 & 20015 & 19288 \\
\hline & $\mathrm{ZT}$ & 503433 & 482715 & 499647 & 500287 & 468795 \\
\hline & Jumlah Generasi & 124 & 324 & 154 & 131 & 451 \\
\hline
\end{tabular}

Untuk menganalisa hasil penelitian AOF diatas, terlebih dahulu dilakukan uji normalitas dan uji homogenitas, agar dapat menentukan penggunaan uji yang membandingkan rata-rata hasil penelitian. Uji normalitas yang digunakan adalah uji Kolmogorov-Smirnov dan uji Shapiro-Wilk, sedangkan uji homogenitas menggunakan uji Levene. Hasil penelitian yang berdistribusi normal dengan variansi yang homogen akan dibandingkan dengan uji ANOVA, sedangkan untuk yang berdistribusi normal dengan variansi tidak homogen menggunakan uji Welch. Khusus untuk hasil penelitian yang tidak berdistribusi normal maka digunakan uji Kruskal-Wallis. Perhitungan uji statistik diatas menggunakan bantuan perangkat lunak SPSS, dengan hasil analisa ditabulasikan dalam tabel dibawah ini.

Tabel 4. Hasil Uji Normalitas AOF

\begin{tabular}{|c|c|c|c|c|c|c|c|c|}
\hline \multirow{2}{*}{\multicolumn{2}{|c|}{ Instance }} & \multirow{3}{*}{$\begin{array}{c}\text { Alpha } \\
0,10\end{array}$} & \multicolumn{3}{|c|}{ Kolmogorov-Smirnov } & \multicolumn{3}{|c|}{ Shapiro-Wilk } \\
\hline & & & Statistic & $\mathrm{df}$ & Sig. & Statistic & $\mathrm{df}$ & Sig. \\
\hline \multirow{8}{*}{ I_150_30 } & \multirow{3}{*}{$\mathrm{ZM}$} & & 0,339 & 5 & 0,062 & 0,794 & 5 & 0,073 \\
\hline & & 0,50 & 0,201 & 5 & 0,200 & 0,889 & 5 & 0,353 \\
\hline & & 0,90 & 0,204 & 5 & 0,200 & 0,945 & 5 & 0,702 \\
\hline & \multirow{3}{*}{ ZT } & 0,10 & 0,268 & 5 & 0,200 & 0,933 & 5 & 0,616 \\
\hline & & 0,50 & 0,340 & 5 & 0,060 & 0,792 & 5 & 0,070 \\
\hline & & 0,90 & 0,218 & 5 & 0,200 & 0,970 & 5 & 0,878 \\
\hline & \multirow{2}{*}{$\begin{array}{c}\text { Jumlah } \\
\text { Generasi }\end{array}$} & 0,10 & 0,218 & 5 & 0,200 & 0,924 & 5 & 0,556 \\
\hline & & 0,50 & 0,194 & 5 & 0,200 & 0,924 & 5 & 0,558 \\
\hline
\end{tabular}




\begin{tabular}{|c|c|c|c|c|c|c|c|c|}
\hline & & 0,90 & 0,142 & 5 & 0,200 & 0,989 & 5 & 0,975 \\
\hline \multirow{9}{*}{ I_250_50 } & \multirow{3}{*}{$\mathrm{ZM}$} & 0,10 & 0,208 & 5 & 0,200 & 0,932 & 5 & 0,611 \\
\hline & & 0,50 & 0,173 & 5 & 0,200 & 0,977 & 5 & 0,920 \\
\hline & & 0,90 & 0,139 & 5 & 0,200 & 0,986 & 5 & 0,962 \\
\hline & \multirow{3}{*}{$\mathrm{ZT}$} & 0,10 & 0,243 & 5 & 0,200 & 0,928 & 5 & 0,582 \\
\hline & & 0,50 & 0,232 & 5 & 0,200 & 0,963 & 5 & 0,831 \\
\hline & & 0,90 & 0,321 & 5 & 0,102 & 0,847 & 5 & 0,186 \\
\hline & \multirow{3}{*}{$\begin{array}{c}\text { Jumlah } \\
\text { Generasi }\end{array}$} & 0,10 & 0,203 & 5 & 0,200 & 0,977 & 5 & 0,917 \\
\hline & & 0,50 & 0,319 & 5 & 0,107 & 0,803 & 5 & 0,085 \\
\hline & & 0,90 & 0,316 & 5 & 0,115 & 0,827 & 5 & 0,131 \\
\hline
\end{tabular}

Hasil uji normalitas pada Tabel 4 dengan uji Kolmogorov-Smirnov dan Shapiro-Wilk, menunjukkan bahwa hasil penelitian AOF untuk ZM, ZT dan Generasi pada $\alpha=0,1,0,5$ dan 0,9 berdistribusi normal dengan taraf signifikansi 0,05 .

Tabel 5. Hasil Uji Homogenitas AOF

\begin{tabular}{|c|c|c|c|c|c|}
\hline \multicolumn{2}{|c|}{ Instance } & Levene Statistic & df1 & df2 & Sig. \\
\hline \multirow{3}{*}{ I_150_30 } & ZM & 3,126 & 2 & 12 & 0,081 \\
\cline { 2 - 6 } & ZT & 1,865 & 2 & 12 & 0,197 \\
\cline { 2 - 6 } & Jumlah Generasi & 2,694 & 2 & 12 & 0,108 \\
\hline \multirow{3}{*}{ I_250_50 } & ZM & 1,084 & 2 & 12 & 0,369 \\
\cline { 2 - 6 } & ZT & 1,948 & 2 & 12 & 0,185 \\
\cline { 2 - 6 } & Jumlah Generasi & 2,130 & 2 & 12 & 0,162 \\
\hline
\end{tabular}

Hasil uji homogenitas pada Tabel 5 dengan uji Levene, menunjukkan bahwa hasil penelitian AOF untuk ZM, ZT dan Generasi pada $\alpha=0,1,0,5$ dan 0,9 mempunyai variansi yang homogen dengan taraf signifikansi 0,05 (kolom Sig. pada tabel 5 bernilai lebih besar dari 0,05). Dari hasil kedua uji, hasil ekperimen AOF berdistribusi normal dengan variansi yang homogen, sehingga digunakan uji ANOVA untuk membandingkan nilai rata-rata ZM, ZT dan Generasi pada $\alpha=0,1,0,5$ dan 0,9 dengan hasil uji ditabulasikan dalam tabel dibawah ini.

Tabel 6. Hasil Uji ANOVA AOF

\begin{tabular}{|c|c|c|c|c|c|c|c|}
\hline \multicolumn{3}{|c|}{ Instance } & Sum of Squares & df & Mean Square & $\mathrm{F}$ & Sig. \\
\hline \multirow{9}{*}{ I_150_30 } & \multirow{3}{*}{$\mathrm{ZM}$} & Between Groups & 1531,600 & 2 & 765,800 & 0,039 & 0,961 \\
\hline & & Within Groups & 232752,800 & 12 & 19396,067 & & \\
\hline & & Total & 234284,400 & 14 & & & \\
\hline & \multirow{3}{*}{ ZT } & Between Groups & 307991120,400 & 2 & 153995560,200 & 2,350 & 0,138 \\
\hline & & Within Groups & 786520738,000 & 12 & 65543394,833 & & \\
\hline & & Total & 1094511858,400 & 14 & & & \\
\hline & \multirow{3}{*}{ Jumah Generasi } & Between Groups & 9004,800 & 2 & 4502,400 & 1,567 & 0,248 \\
\hline & & Within Groups & 34475,600 & 12 & 2872,967 & & \\
\hline & & Total & 43480,400 & 14 & & & \\
\hline \multirow{9}{*}{ I_250_50 } & \multirow{3}{*}{$\mathrm{ZM}$} & Between Groups & 38488,133 & 2 & 19244,067 & 0,389 & 0,686 \\
\hline & & Within Groups & 593259,600 & 12 & 49438,300 & & \\
\hline & & Total & 631747,733 & 14 & & & \\
\hline & \multirow{3}{*}{$\mathrm{ZT}$} & Between Groups & 491090575,600 & 2 & 245545287,800 & 0,384 & 0,689 \\
\hline & & Within Groups & 7674834746,400 & 12 & 639569562,200 & & \\
\hline & & Total & 8165925322,000 & 14 & & & \\
\hline & \multirow{3}{*}{$\begin{array}{l}\text { Jumlah } \\
\text { Generasi }\end{array}$} & Between Groups & 21612,133 & 2 & 10806,067 & 0,727 & 0,503 \\
\hline & & Within Groups & 178319,200 & 12 & 14859,933 & & \\
\hline & & Total & 199931,333 & 14 & & & \\
\hline
\end{tabular}

Hasil uji ANOVA, menunjukkan bahwa nilai rata-rata ZM, ZT dan Generasi tidak memiliki perbedaan signifikan untuk nilai $\alpha=0,1,0,5$ dan 0,9 pada taraf signifikansi 0,05 (nilai kolom Sig pada Tabel 6 lebih besar dari 0,05). Hal ini berarti perubahan $\alpha$ tidak berpengaruh secara signifikan terhadap perubahan nilai rata-rata dari fungsi objektif ke-1 (ZM), fungsi objektif ke-2 (ZT) dan jumlah Generasi. Algoritma Genetika untuk optimasi AOF menerapkan operator PPX dan Remove dan insert yang sama dengan Operator Genetika untuk tahapan NSGA-II dengan parameternya sebagaimana ditabulasikan pada Tabel 7 dibawah ini.

Tabel 7.Parameter Algoritma Genetika untuk AOF

\begin{tabular}{|l|l|l|}
\hline No & Nama Paramater & Nilai \\
\hline 1 & Jumlah Populasi & 20 \\
\hline 2 & Bobot $(\alpha)$ & 0,1 \\
\hline
\end{tabular}




\begin{tabular}{|l|l|l|}
\hline 3 & Probability of Crossover $\left(\mathrm{P}_{\mathrm{c}}\right)$ & 0,9 \\
\hline 4 & Probability of Mutation $\left(\mathrm{P}_{\mathrm{m}}\right)$ & 0,1 \\
\hline
\end{tabular}

Untuk menunjukkan perubahan populasi berkaitan dengan bertambahnya generasi, maka Gambar 3 menampilkan populasi Algoritma Genetika untuk penjadwalan mesin produksi pada saat inisialisasi populasi, generasi ke-50 dan 73. Ternyata nilai fungsi objektif ke-1 (ZM) dan nilai fungsi objektif ke-2 (ZT) selalu lebih baik dari generasi sebelumnya.

\subsubsection{Optimasi Penjadwalan Mesin Produksi Menggunakan NSGA-II}

Untuk mendapatkan sekumpulan solusi pareto-optimal terbaik dengan efisien, perlu dilakukan percobaan untuk menentukan jumlah generasi terkecil yang dibutuhkan untuk mendapatkan solusi paretooptimal. Kualitas kumpulan solusi pareto-optimal dari generasi yang berbeda dibandingkan berdasarkan estimasi rata-rata dari indikator hypervolume. Indikator hypervolume diestimasi menggunakan pendekatan Monte Carlo, yaitu dengan menormalisasi nilai semua fungsi objektif antara 0 dan 1 , kemudian membangkitkan sekumpulan nilai fungsi objektif secara acak, dan menguji setiap nilai fungsi objektif acak tersebut apakah didominasi salah solusi pareto-optimal.

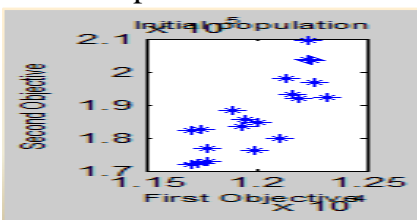

(i) Inisialisasi Populasi

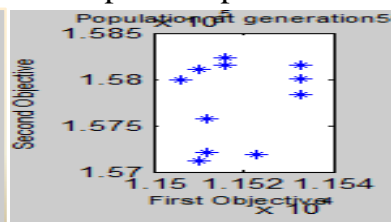

(ii) Populasi Generasi ke-50

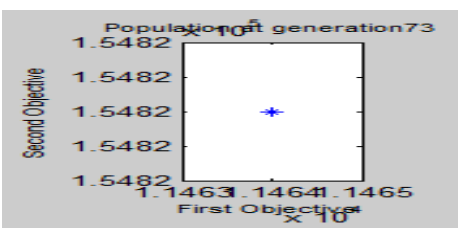

(iii) Populasi Generasi ke-73

Gambar 3. Populasi pada Algoritma Genetika untuk Makespan dan Total Tardiness

Penelitian untuk estimasi hypervolume dilakukan sebanyak dua kali untuk setiap instance pada generasi yang sama, yang hasilnya ditabulasikan ke dalam Tabel 8 dibawah ini.

Tabel 8. Hasil Penelitian Estimasi Hypervolume NSGA-II

\begin{tabular}{|c|c|c|c|c|c|c|}
\hline \multirow{2}{*}{ Instance } & \multicolumn{5}{|c|}{ Estimasi Hypervolume pada Penelitian ke- } & \multirow{2}{*}{ Rata-rata } \\
\cline { 2 - 7 } & 1 & 2 & 3 & 4 & 5 & \\
\hline I_250_50 & 0,74693 & 0,56053 & 0,62099 & 0,43587 & 0,79323 & 0,6315100 \\
\hline I_150_30 & 0,44204 & 0,54995 & 0,69228 & 0,7856 & 0,62527 & 0,6190280 \\
\hline
\end{tabular}

Pengujian normalitas dengan SPSS terhadap data pada Tabel 8 ditabulasikan ke dalam tabel 9

Pengujian normalitas adalah pengujian tentang kenormalan distribusi data. Uji ini merupakan pengujian yang paling banyak dilakukan untuk analisis statistik parametrik. Karena data yang berdistribusi normal merupakan syarat dilakukannya tes parametrik.

Tabel 9. Hasil Uji Normalitas Estimasi Hypervolume NSGA-II

\begin{tabular}{|c|c|c|c|c|c|c|c|}
\hline \multirow{2}{*}{ Instances } & \multicolumn{3}{c|}{ Kolmogorov-Smirnov } & \multicolumn{3}{c|}{ Shapiro-Wilk } \\
\cline { 3 - 8 } \multicolumn{2}{|c|}{} & Statistic & df & Sig. & Statistic & df & Sig. \\
\hline \multirow{2}{*}{ Hypervolume } & I_150_30 & 0,119 & 5 & 0,200 & 0,997 & 5 & 0,997 \\
\cline { 2 - 9 } & I_250_50 & 0,189 & 5 & 0,200 & 0,963 & 5 & 0,827 \\
\hline
\end{tabular}

Parameter yang digunakan untuk penelitian optimasi penjadwalan mesin produksi dengan NSGA-II ditabulasikan ke dalam Tabel 10 hampir sama dengan parameter Algoritma Genetika untuk AOF.

Untuk menunjukkan perubahan populasi berkaitan dengan bertambahnya generasi, maka Gambar 4 menampilkan populasi NSGA-II pada saat inisialisasi populasi, generasi ke-100, 250, 500, 750 dan 1000.

Tabel 9. Parameter NSGA-II

\begin{tabular}{|c|l|c|}
\hline No & Nama Paramater & Nilai \\
\hline 1 & Jumlah Populasi & 20 \\
\hline 2 & Generasi & 1000 \\
\hline 3 & Probability of Crossover $\left(\mathrm{P}_{\mathrm{c}}\right)$ & 0,9 \\
\hline 4 & Probability of Mutation $\left(\mathrm{P}_{\mathrm{m}}\right)$ & 0,1 \\
\hline
\end{tabular}



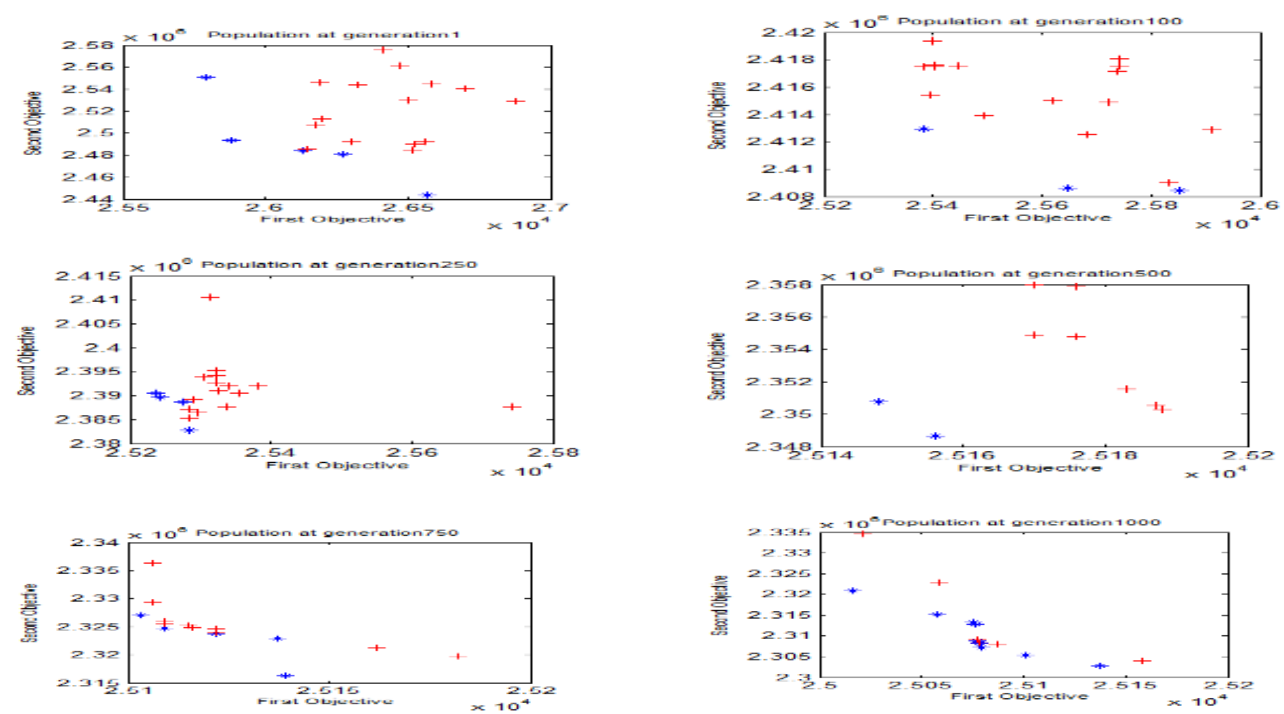

Gambar 4. Populasi pada NSGA-II untuk Makespan dan Total Tardiness

Pada Gambar 4 terlihat bahwa 20 solusi yang terdapat pada populasi semakin tersebar merata mendekati solusi pareto-optimal dengan semakin bertambahnya jumlah generasi. Bersamaan dengan bertambahnya generasi, maka nilai fungsi objektif ke-1 dan ke-2 akan semakin mengecil secara bersamasama. Terlihat bahwa dari 20 solusi yang dihasilkan, tidak semuanya merupakan solusi pareto, optimal, pada contoh gambar ini hanya ada 12 solusi pareto optimal yang berada pada front 1 (disimbolkan dengan '*' bewarna biru), sedangkan 8 solusi lainya berada pada front 2 (simbol '+' berwarna merah). Populasi yang didapat pada generasi ke-1000 NSGA-II ditabulasikan kedalam Tabel 10 dibawah ini.

Tabel 10. Populasi NSGA-II pada generasi ke-1000

\begin{tabular}{|c|c|c|c|c|}
\hline Solusi ke- & $\mathrm{Z}_{\mathrm{M}}$ & $\mathrm{Z}_{\mathrm{T}}$ & Front & Crowding Distance \\
\hline 1 & 25101 & 2305256 & 1 & 0,321962797 \\
\hline 2 & 25075 & 2313357 & 1 & 0,281232594 \\
\hline 3 & 25078 & 2308285 & 1 & 0,067711391 \\
\hline 4 & 25076 & 2312753 & 1 & 0,263258517 \\
\hline 5 & 25058 & 2315153 & 1 & 0,900309604 \\
\hline 6 & 25078 & 2308285 & 1 & 0 \\
\hline 7 & 25077 & 2308887 & 1 & 0,263148123 \\
\hline 8 & 25079 & 2307208 & 1 & 0,357273681 \\
\hline 9 & 25137 & 2302717 & 1 & 65535 \\
\hline 10 & 25078 & 2308285 & 1 & 0,041492922 \\
\hline 11 & 25016 & 2320834 & 1 & 65535 \\
\hline 12 & 25101 & 2305256 & 1 & 0,405264769 \\
\hline 13 & 25021 & 2334534 & 2 & 65535 \\
\hline 14 & 25158 & 2304022 & 2 & 65535 \\
\hline 15 & 25087 & 2308031 & 2 & 0,726049629 \\
\hline 16 & 25077 & 2308971 & 2 & 0,613319063 \\
\hline 17 & 25078 & 2308358 & 2 & 0,018016365 \\
\hline 18 & 25078 & 2308358 & 2 & 0 \\
\hline 19 & 25059 & 2322840 & 2 & 1,246560645 \\
\hline 20 & 25078 & 2308358 & 2 & 0 \\
\hline
\end{tabular}

\subsubsection{Perbandingan AOF dan NSGA-II}

Solusi-solusi dari permasalahan multi-objective dapat dibandingkan dengan menggunakan dominasi. Solusi ke-i dinyatakan lebih baik dari solusi ke-j jika solusi ke-i mendominasi solusi ke-j. Solusi ke-i mendominasi solusi ke-j apabila semua nilai fungsi objektif solusi ke-i tidak lebih buruk dari solusi ke-j, dan minimal satu nilai fungsi objektif solusi ke-i mempunyai nilai yang lebih baik dari fungsi objektif solusi ke-j.Perbandingan dominasi dilakukan antara solusi Algoritma Genetika AOF untuk $\alpha=0.1$ dan solusi 
NSGA-II. Digunakan simbol 'M' untuk mendominasi, simbol 'D' untuk didominasi, dan simbol '_' berarti solusi tidak saling mendominasi.

Tabel 11. Perbandingan dominasi Solusi AOF dengan Solusi NSGA-II untuk Instance I_150_30

\begin{tabular}{|c|c|c|c|c|c|c|c|c|c|c|}
\hline \multirow{2}{*}{ Solusi } & \multicolumn{10}{|c|}{ NSGA-II } \\
\cline { 2 - 11 } & 1 & 2 & 3 & 4 & 5 & 6 & 7 & 8 & 9 & 10 \\
\hline AOF1 & - & - & - & - & - & - & - & - & - & - \\
\hline AOF2 & - & - & - & - & - & - & - & - & - & - \\
\hline AOF3 & - & - & - & - & - & - & - & - & - & - \\
\hline AOF4 & - & - & - & - & - & - & - & - & - & - \\
\hline AOF5 & - & - & - & - & - & - & - & - & - & - \\
\hline
\end{tabular}

Tabel 12. Perbandingan dominasi Solusi AOF dengan Solusi NSGA-II untuk Instance I_250_50

\begin{tabular}{|c|c|c|c|c|c|c|c|c|c|c|}
\hline \multirow{2}{*}{ Solusi } & \multicolumn{10}{|c|}{ NSGA-II } \\
\cline { 2 - 11 } & 1 & 2 & 3 & 4 & 5 & 6 & 7 & 8 & 9 & 10 \\
\hline AOF1 & - & - & - & - & - & - & - & - & - & - \\
\hline AOF2 & - & - & D & - & D & - & - & - & D & D \\
\hline AOF3 & D & D & D & D & D & D & D & D & D & D \\
\hline AOF4 & D & D & D & D & D & D & D & D & D & D \\
\hline AOF5 & D & D & D & D & D & D & D & D & D & D \\
\hline
\end{tabular}

Hasil perbandingan dominasi solusi AOF dengan solusi NSGA-II pada Tabel 11 s.d Tabel 12 menunjukkan bahwa selalu ada solusi AOF yang didominasi oleh solusi NSGA-II, sedangkan solusi AOF tidak ada yang mendominasi solusi NSGA-II. Hal ini berarti solusi pareto-optimal NSGA-II berhasil memberikan solusi yang lebih baik dari solusi AOF. Berdasarkan perbandingan diatas, terlihat bahwa populasi solusi pareto-optimal NSGA-II lebih baik dengan berhasil mendominasi $100 \%$ solusi sistem AOF. Begitu juga perbandingan solusi NSGA-II terhadap solusi AOF menunjukkan bahwa populasi solusi paretooptimal NSGA-II lebih baik dengan berhasil mendominasi $100 \%$ solusi AOF.

\section{KESIMPULAN}

\subsection{Kesimpulan}

Dari hasil penelitian dan pembahasan yang telah dilakukan untuk menjawab setiap topik permasalahan, maka dapat disimpulkan beberapa hal sebagai berikut :

1. Hasil penelitian pada NSGA-II diperoleh 20 solusi yang terdapat pada populasi semakin tersebar merata mendekati solusi pareto-optimal dengan semakin bertambahnya jumlah generasi, dan bersamaan dengan bertambahnya generasi maka nilai makespan dan total tardiness akan semakin minimal secara bersamasama.

2. Hasil analisa solusi pareto-optimal yang dihasilkan NSGA-II menunjukkan bahwa solusi pareto-optimal lebih baik dengan mendominasi $100 \%$ solusi dari sistem yang dihasilkan Algoritma Genetika dengan Aggregat of Function (AOF).

4.2 Saran

1. Solusi pareto optimal dapat ditingkatkan kualitasnya dengan melakukan penelitian lebih mendalam terhadap parameter yang mempengaruhi solusi NSGA-II seperti Probabilitas Crossover dan Probabilitas Mutasi

2. Selain penelitian terhadap parameter, solusi pareto-optimal dapat ditingkatkan kualitasnya dengan melakukan penelitian terhadap operator genetika lain yang dapat diterapkan pada penjadwalan mesin produksi dengan NSGA-II.

3. Pengembangan lebih lanjut diperlukan untuk dapat menyelesaikan permasalahan penjadwalan mesin produksi yang lebih kompleks, seperti penjadwalan mesin produksi yang juga mempertimbangkan jenis multiobjektif yang lainnya.

\section{UCAPAN TERIMA KASIH}

Penulis menyampaikan ucapan terima kasih sebesar-besarnya kepada Direktorat Riset dan Pengabdian Masyarakat, Direktorat Jenderal Penguatan Riset dan Pengembangan, Kementerian Riset, Teknologi, dan Pendidikan Tinggi. Penulis sekaligus sebagai peneliti mendapatkan pembiayaan dalam menyelesaikan penelitian dan tulisan ini. 


\section{REFERENSI}

Balasundaram, R., Valavan, D. \& Baskar, N. "Heuristic Based Approach for BI-Criteria Optimization of Minimizing Makespan and Total Flow Time of Flowshop Scheduling”. International Journal of Mechanical \& Mechatronics Engineering IJMME-IJENS Vol:14 No:02, 2014.

Chakraborty, U.K. \& Laha, D. An improved heuristic for permutation flowshop scheduling. Int. J. Information and Communication Technology, Vol. 1, No. 1, 2007.

Choudhury, B.B., Mishra, D. \& Biswal, B.B. "Task assignment and scheduling in a constrained manufacturing system using GA". International Journal Agile System \& Management (IJASM). 2007.

Deb, K. \& Tiwari, S. "Omni-optimizer: A generic evolutionary algorithm for single and multi-objective optimization". European Journal of Operational Research 185 (2008) 1062-1087. Elsevier. 2008.

Deb, K. "Multi-Objective Optimization Using Evolutionary Algorithms: An Introduction". Department of Mechanical Engineering Indian Institute of Technology Kanpur, PIN 208016, India. KanGAL Report Number 2011003. Springer, 2011.

Eva Instances. http://www.upv.es/gio/rruiz, diakses april 2015, 11.30 wib

Ginting, R. 2009. Penjadwalan Mesin. Graha Ilmu. Yogyakarta.

Josezefowiez, N., Semet, F. \& Talbi, E. "Multi-objective vehicle routing problems". European Journal of Operational Research 189 (2008) 293-309. Elsevier. 2008.

Mishra, S.K., Panda, G. \& Meher, S. "Comparative Performance Evaluation of Multiobjective Optimization Algorithm For Portfolio Management". Presented International Symposium on Biologically Inspired Computing and Application (BICA-2009). Bhubaneswar, India. December 2009.

Ruiz, R., Minella, G. \& Ciavotta, M. "A review and evaluation of multi-objective algorithms for the flowshop scheduling problem”. Grupo de Sistemas de Optimización Aplicada. 29 Maret 2007

Tyagi, N., Seidgar, H., Abedi, M. \& Chandramouli, A.B. "Learning and Forgetting Effects of Flexible Flow shop Scheduling". International Journal of Innovation and Applied Studies . ISSN 2028-9324 Vol. 7 No. 3 Aug. 2014, pp. 857-867, 2014.

Yagmahan, B. \& Yenisey, M.M. 2010. "A multi-objective ant colony system algorithm for flow shop scheduling problem". Journal Expert Systems with Applications. Elsevier.

Zitzler, E., Thiele, L., Laumanns, M., Fonseca, C. M. \& Fonseca, G. 2002. Performance Assessment of Multiobjective Optimizers: An Analysis and Review. TIK-Report No. 139. Institut f'ur Technische Informatik und Kommunikationsnetze, ETH Z"urich Gloriastrasse 35, ETH-Zentrum, CH-8092 Z"urich, Switzerland.

Zitzler, E. \& Thiele, L. 1998. Multiobjective Optimization Using Evolutionary Algorithms-A Comparative Case Study. Parallel Problem Solving from Nature PPSN V Amsterdam. Page 292 301. Springer.

\section{BIBLIOGRAFI PENULIS}

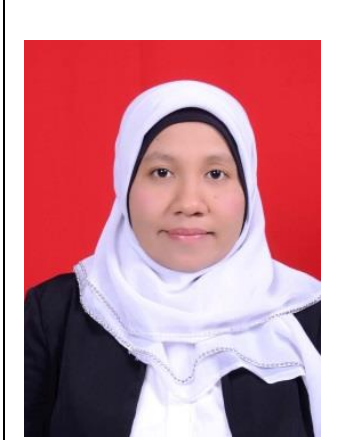

Fifin Sonata lahir di Banyuwangi, 24 Desember 1982. Menyelesaikan studi Magister (S2) di Fakultas Ilmu Komputer dan Teknologi Informasi (FASILKOM) Universitas Sumatera Utara. Saat ini bekerja sebagai Dosen S1 di Sekolah Tinggi Ilmu Komputer Medan dengan mengampu mata kuliah Analisa Perancangan Sistem Informasi, Struktur Data dan Pemrograman. Selain mengajar di kampus tersebut penulis juga mengajar sebagai Dosen freelance di Sekolah Tinggi Manajemen dan Informatika Komputer Triguna Dharma,. Selain itu penulis aktif mengikuti event yang diselenggarakan Pemerintah maupun swasta. Penulis merupakan copy editor pada Jurnal Kementerian Komunikasi dan Informatika Republik Indonesia (KOMINFO) Medan dan Koordinatoor Bidang Kerjasama pada Asosiasi Peneliti Sumatera Utara (APSU). Penulis juga aktif menulis pada beberapa jurnal diantaranya : Sistem Penjadwalan Mesin Produksi Menggunakan Algoritma Johnson dan Campbell, Jurnal Buana Informatika, Universitas Atma Jaya Yogyakarta; Optimasi Makespan dan Total Tardiness Dalam Penjadwalan Mesin Produksi Type Flow shop Menggunakan Metode Non-Dominated Sorting Genetic Algorithm (NSGA-II), Jurnal Teknologi Informasi dan Komunikasi (JTIK), Kementerian Komunikasi dan Informatika Republik Indonesia (KOMINFO), Vol. 5/No. 1/2016 Juni 2016 p-ISSN: 2338-5839 e-ISSN: 2548-7582; Implementasi Metode Simple Additive Weighting (SAW) Dengan Proses Fuzzifikasi Dalam Penilaian Kinerja Dosen, Jurnal Teknologi Informasi dan Komunikasi (JTIK), Kementerian Komunikasi dan Informatika Republik Indonesia (KOMINFO), Vol. 5/No.2/2016 Desember 2016 p-ISSN: 2338-5839 e-ISSN: 2548-7582; Analisis Survei Faktor-Faktor Knowledge Sharing Dengan Teknik Focus Group Discussion (Fgd) Di Stikom Medan, Jurnal Teknologi Informasi dan Komunikasi (JTIK), Kementerian Komunikasi dan Informatika Republik Indonesia (KOMINFO), Vol.6 No. 1, Juni 2017 p ISSN: 2338-5839 eISSN: 2548-7582; Pemanfaatan Metode Analitycal Hierarchy Process (Ahp) Dalam Studi 


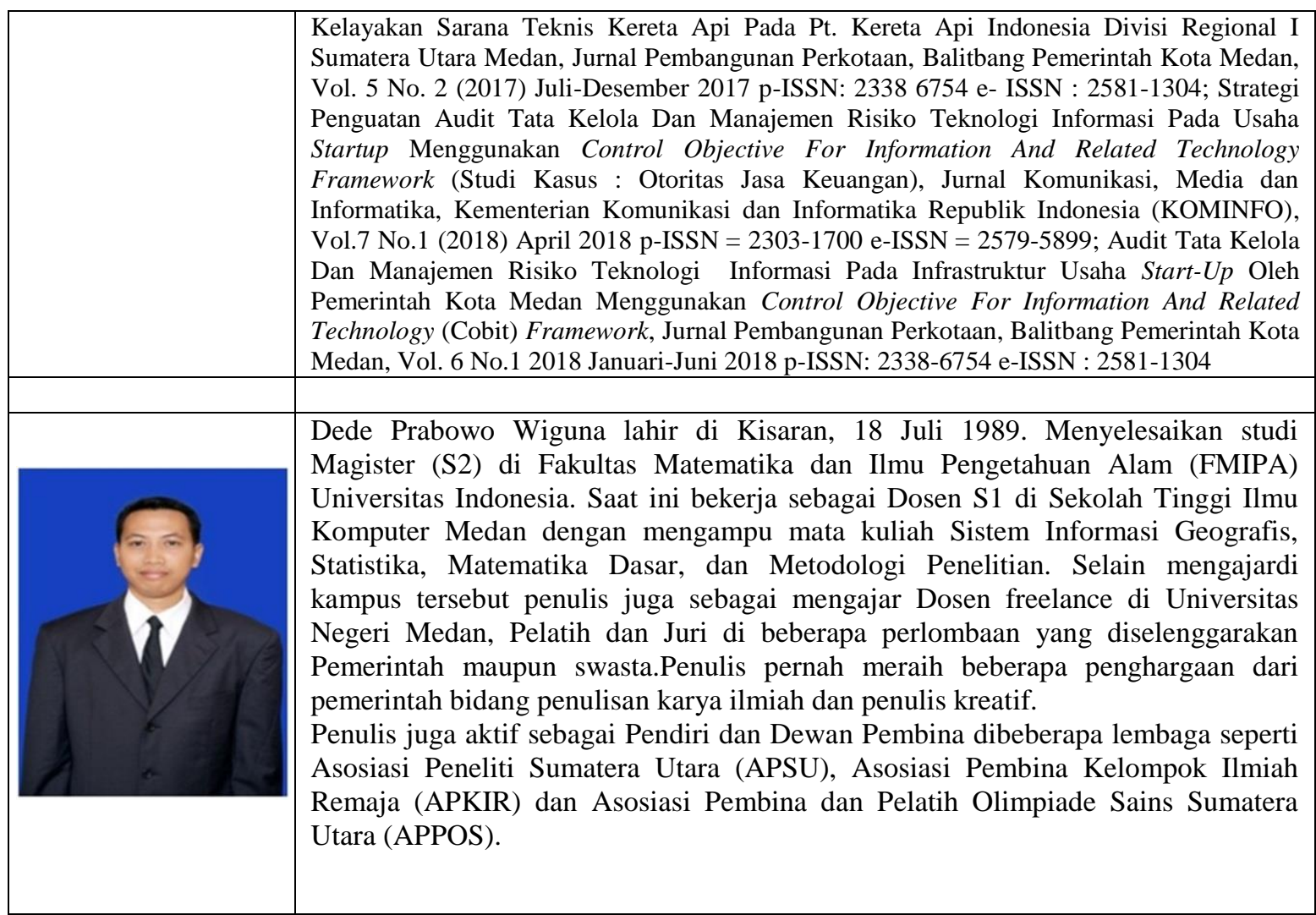

